\title{
Tricobezoar gastric gigant la o adolescentă cu tricotilomanie
}

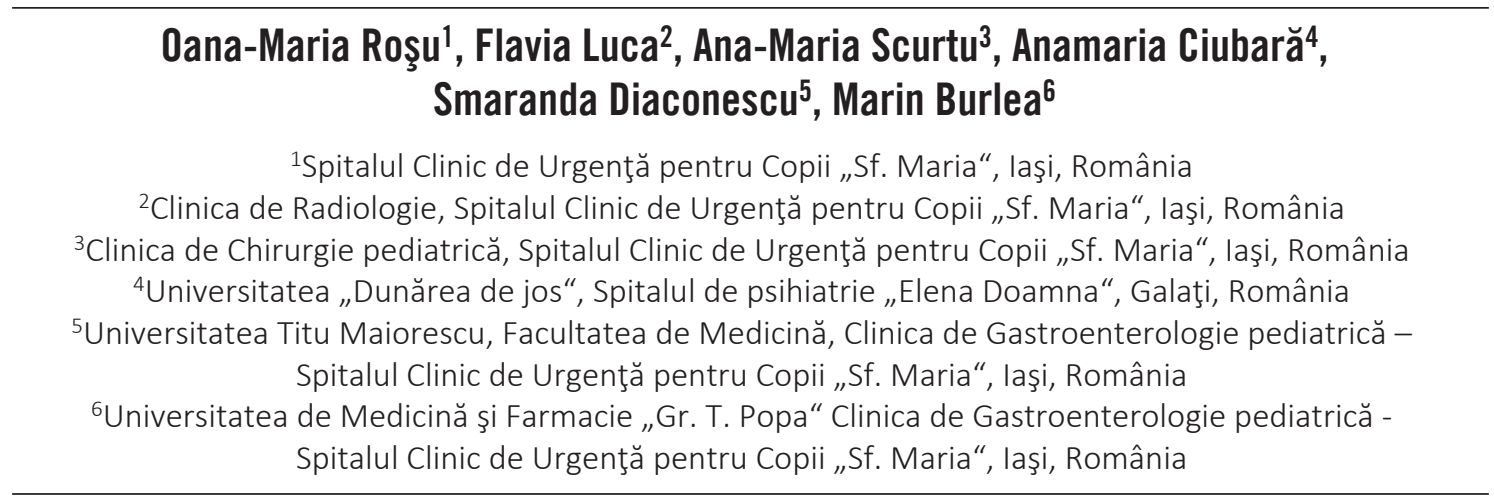

\begin{abstract}
REZUMAT
Introducere. Bezoarul este un conglomerat alcătuit din material parţial digerabil sau nedigerabil impactat la nivelul stomacului. Tricobezoarul (aglomerările de păr) apare cel mai frecvent la pacienţii cu tulburări psihice (tricotilomanie) şi reprezintă o patologie rară care poate determina dificultăţi diagnostice si terapeutice.

Material şi metodă. Prezentăm un caz de tricobezoar gastric la o pacientă in varsta de 12 ani, fără antecedente personale patologice, internată pentru epigastralgii şi vărsături alimentare. Examenul clinic relevă la palparea abdomenului o formaţiune epigastrică de aprox. $5 / 3 \mathrm{~cm}$, dură, imobilă, aderentă de planul profund la care examenele de laborator relevă doar o uşoară anemie hipocromă microcitară. Endoscopia digestivă superioară vizualizează tricobezoar gigant de aprox $17 \mathrm{~cm}$, vizibil din zona subcardială până în regiunea antrală, fixat cu un fir de păr de o zonă cu aspect inflamator pseudopolipoid, situata prepiloric. Pacienta a fost dirijată către serviciul de chirurgie pediatrică, întrucât dimensiunea tricobezoarului nu a permis extragerea pe cale endoscopică. S-a tentat initial extragere prin abord laparoscopic, care nu a reuşit si a impus laparotomie minimă subcostală stângă, gastrotomie cu evacuarea tricobezoarului gastric. Postoperator evoluţie favorabilă.

Discuţii. Cu toate că prevalenţa la om este scăzută, mortalitatea poate atinge în anumite cazuri $30 \%$, datorită sângerărilor, obstrucţiei, peritonitei sau eventualei perforaţii gastrointestinale ce pot apărea. Diverse metode endoscopice au fost raportate pentru extragerea bezoarului, precum litotripsie cu unde şoc, îndepărtare prin aspirare folosind endoscop cu canal larg de lucru, extracţie cu ansă de polipectomie şi forceps de biopsie. Concluzie. Raritatea acestei patologii în populaţia pediatrică impune un diagnostic diferenţial atent. Dificultăţile terapeutice se datorează dimensiunilor tricobezoarului, iar prognosticul depinde de patologia psihiatrică subiacentă.
\end{abstract}

Cuvinte cheie: tricobezoar, tricotilomanie, endoscopie

\section{INTRODUCERE}

Bezoarii sunt conglomerate de material nedigerabil, precum părul, care sunt de obicei localizați în stomac. Bezoarii sunt cunoscuți în literatură încă din secolul al XII-lea, fiind descrişi iniţial în India. Datorită rarităţii lor şi a patogenezi neclare, în acea vreme s-au dat bezoarilor proprietăți speciale. Numele Bezoar, provine din cuvântul arab „Bedzehr“", persan „Padzahr“ sau ebraic „Beluzaar“, toate având sens de antidot. Pe baza compoziţiei lor, bezoarii au fost clasificați în patru tipuri: fitobezoar (din fibre vegetale), tricobezoar (din păr), lactobezoar (lactate), precum şi diverse (medicamente, nisip, hârtie absorbantă) $(1,2)$. Cea mai frecventă formă de bezoar este fitobezoarul, care este format din celuloză. A doua formă comună o reprezintă tricobezoarul, cel mai adesea cauzat de tricofagie (in- 
gestia de păr), combinată cu o boală psihică (tricotilomanie). Tricotilomania, dorința irezistibilă de a extrage propriul păr, a fost descrisă pentru prima dată de către Hallopeau în anul 1889, iar primul caz de trichobezoar a fost raportat cu un secol mai devreme, în anul 1792 de către Baudamant $(3,4)$. Această stare patologică afectează în special fetele tinere, cu sau fără tulburări psihiatrice cunoscute.

\section{PREZENTARE DE CAZ}

Pacientă de 12 ani, fără antecedente personale patologice semnificative, este admisă în secția clinică de Gastroenterologie pediatrică, fiind dirijată dintr-un spital din teritoriu, cu suspiciunea de tumoră gastrică. La internare, pacienta prezenta epigastralgii şi vărsături alimentare. Ancheta familială nu relevă conflicte intrafamiliale generatoare de stres psihologic. Palparea epigastrului evidențiază o formațiune dură, imobilă, aderentă de planul profund, de aprox $5 / 3 \mathrm{~cm}$. Paraclinic se decelează anemie hipocromă microcitară, fără alte modificări patologice. Ecografia abdominală vizualizează o zonă cu aspect hiperecogen, cu con de umbră posterior, care ocupă epigastrul şi mezogastrul (Fig.1).

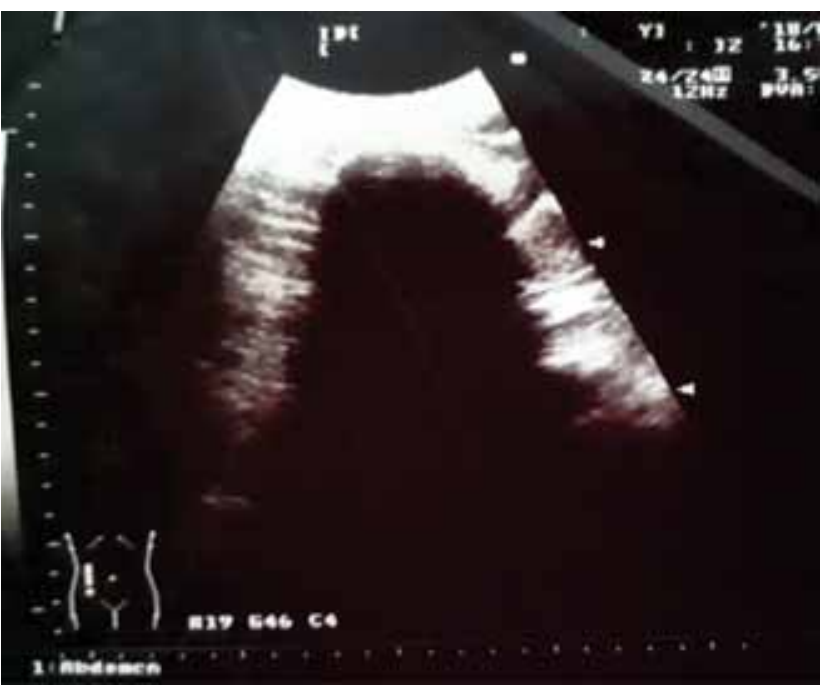

FIGURA 1. Ecografie abdominală - zonă cu aspect hiperecogen, cu con de umbră posterior

Endoscopia vizualizează o masă de aprox 17 cm, vizibilă din zona subcardială până în regiunea antrală, fixată cu un fir de păr de o zonă cu aspect inflamator pseudopolipoid, situata prepiloric (Fig. 2).

S-a efectuat consult neuropsihiatric ce pune diagnosticul de tricotilomanie, recomandându-se consiliere psihologică şi risperidona $0,5 \mathrm{mg} / \mathrm{zi}$, timp de 30 zile. Examenul CT abdominal descrie o masă de țesut moale, neomogenă, cu incluziuni aerice, vizibilă intraluminal gastric, cu denstităţi de tip solid,

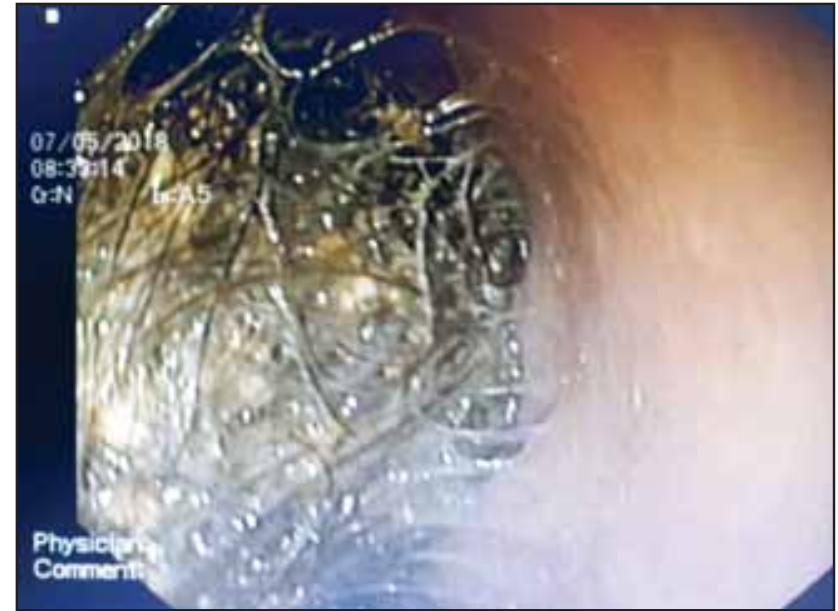

FIGURA 2. Imagine endoscopică a tricobezoarului

fără priză de contrast, bine delimitată, cu dimensiuni de aprox. 109/39 mm ce ocupa regiunea corporeo-antrală, până la nivelul canalului piloric, stomac dilatat, cu pereți discret îngroşați circumferențial, regiunea antrală gastrică cu diametru anteroposterior de $60 \mathrm{~mm}$ si pilorul cu pereți îngroşați circumferențial de aprox. 6,4 mm (Fig. 3).

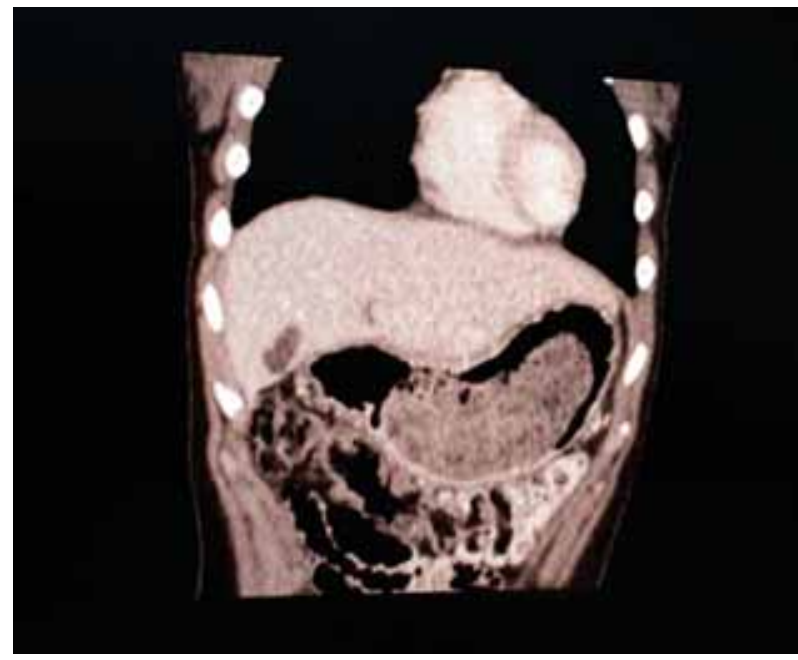

FIGURA 3. CT abdominal - masă de țesut moale, neomogenă, cu incluziuni aerice

Din cauza dimensiunilor tricobezoarului nu a fost posibilă extragerea endoscopică, motiv pentru care pacienta a fost transferată în serviciul de chirurgie pediatrică, iniţial optându-se pentru extragerea prin laparoscopie convertita insa in chirurgie clasică (minimă laparotomie subcostală stângă, gastrotomie cu evacuarea tricobezoarului gastric) (Fig. 4).

Evoluția postoperatorie a fost favorabilă; adolescenta se externează după 10 zile de la intervenţia chirurgicală, rămânând în atenția echipei multidisciplinare gastroenterolog, chirurg şi neuropsihiatru pentru monitorizare în dinamică. 


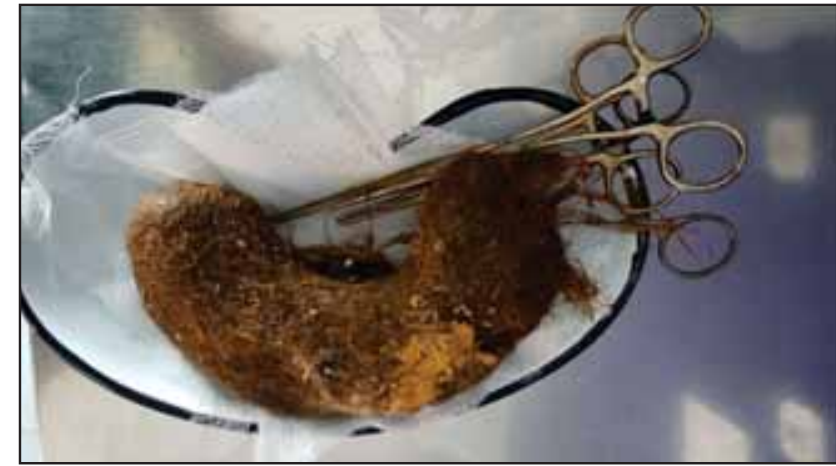

FIGURA 4. Tricobezoar gastric-piesa operatorie

\section{DISCUŢII}

Tricobezoarul este cea mai frecventă formă de bezoar întâlnită la populația tânără. În revizuirea clasică realizată de DeBakey şi Ochsner, 80\% dintre cazuri au fost întâlnite la pacienții sub 30 ani. Prin ingerarea părului, a fibrelor din covoare sau îmbrăcăminte se formează o masa care ulterior se blochează între pliurile mucoasei gastrice, deoarece suprafața alunecoasă împiedică propulsia realizată de undele peristaltice (5). Tricobezoarul este unic şi ia în general forma stomacului (6-8). Mucusul care îl acoperă îi conferă acestuia o suprafață lucioasă, strălucitoare, iar prin descompunerea şi fermentarea grăsimilor rezultă mirosul fetid caracteristic. Prin digestia peptică a proteinelor firului de păr, tricobezoarul capata in cele mai multe cazuri o culoare neagră, indiferent de culoarea originală a părului ingerat $(9,10)$

Studiile din literatură relevă că tricobezoarul este frecvent întâlnit la populația sub 30 ani, dar prevalență este mai ridicată la pacientii de sex feminin cu varsta sub 20 ani. Acuzele comune includ dureri abdominale, grețuri şi vărsături, balonare, sațietate precoce, scădere ponderală, diaree sau constipație. Nu există insa semne caracteristice sau simptome patognomonice pentru bezoari. În concordanță cu aceste constatări, în cazul nostru pacienta a prezentat simptomatologie nespecifică. Tricobezoarii cu evoluție îndelungată pot provoca complicații, care includ apariția anemiei, hematemezei, ulcerului gastric, obstrucției intestinale, perforației, peritonitei, pancreatitei, icterului obstructiv, sindromului de malabsorbție, invaginațiilor şi apendicitei (11). Standardul de aur în diagnostic este endoscopia digestivă superioară care asigură vizualizarea directă a bezoarului şi permite gestul terapeutic. Terapia endoscopică poate fi eficientă pentru bezoarii compuşi din material vegetal (fitobezoari) şi din lapte (lactobezoari), deoarece acestia sunt de dimensiuni reduse, dar este mai puţin probabil să fie eficace pentru tricobezoari, în special cei de dimensiuni mari $(>20 \mathrm{~cm})$. Diverse alte metode, cum ar fi litotriția extracorporală cu administrarea intragastrică de enzime (lipaza pancreatică, celulază) şi medicamente (metoclopramid, acetilcisteină) demonstrează eficiența diferită (12)

Tricotilomania este o afecțiune curentă, definită ca o afectare a controlului impulsului, caracterizată prin tragerea repetată de păr. Prevalența tricotilomaniei pe parcursul vieții este estimată la între $0,6 \%$ şi $4,0 \%$ din populația globală (13). Tricotilomania este diagnosticată la toate grupele de vârstă; debutul este mai frecvent în timpul preadolescenței şi al adulților tineri, cu o vârstă medie de debut cuprinsă între 9 şi 13 ani şi un vârf notabil la 12-13 ani. La copiii de vârstă preşcolară, tricotilomania este considerată benignă, începe adesea în momentele de stres psihosocial din familie şi aproape niciodată nu continuă odată cu creşterea în vârstă. În rândul copiilor preşcolari, repartitia pe sexe este aproximativ egală; se pare că există o predominanță feminină printre preadolescenți (70-93\%) iar în rândul adulților proporția este de 3 la 1 in favoarea femeilor $(14,15)$.

Conform D.S.M.-IV-2003 sunt stabilite următoarele criterii de diagnostic pentru această tulburare: a. incapacitatea recurentă de a rezista impulsurilor de smulgere a părului propriu, ducând la o pierdere notabilă a acestuia; $b$. creşterea senzaţiei de tensiune imediat înaintea smulgerii părului; c. senzația de plăcere, gratificare sau uşurare în momentul smulgerii părului; d. comportamentul cauzează suferință sau deteriorare semnificativă în domeniile importante sociale; d. nu există nicio asociere cu o inflamație preexistentă a tegumentelor şi nu apare ca răspuns la idei delirante sau halucinații $(16,17)$. Pacienții încearcă să ascundă acest comportament sau să camufleze aria afectată de la nivelul scalpului, pierderea părului fiind caracterizată prin şuviţe scurte, rupte, care apar împreună cu firele de păr normal. Diagnosticul de tricotilomanie se suspicionează atunci când comportamentul compulsiv de smulgere a părului nu este justificat de o condiție medicală generală (de exemplu o afectiune dermatologică) sau de o altă tulburare psihiatrică (precum comportament delirant sau ca rezultat al unor halucinaţii) şi este confirmat prin endoscopie digestivă superioară. Deoarece stresul emoțional de bază este de multe ori un factor declanşator pentru tricofagia sau tricotilomania observată la pacienții afectați, evaluarea psihiatrică sau psihologică este esențială.

Gestionarea şi tratamentul unui bezoar trebuie să cuprindă îndepărtarea masei şi prevenirea recu- 
rențelor, prin abordarea cauzei fizice sau emoționale, care stau la baza apariției acestei patologii. În funcție de consistența, mărimea şi localizarea sa, îndepărtarea bezoarului se poate efectua prin endoscopie sau intervenție chirurgicală - eliminare prin gastrotomie prin laparotomie mediană superioară. Deşi nu este aprobat în mod specific un tratament medicamentos pentru tricotilomanie, unele medicamente pot ajuta la controlarea anumitor simptome, precum antidepresivelecum ar fi clomipramina. Alte medicamente despre care cercetările sugerează că pot avea unele beneficii conțin N-acetilcisteina, un aminoacid care influențează neurotransmiţătorii legați de starea de spirit şi olanzapina, un antipsihotic uşor (18-20). Strategii comportamentale eficiente în tratamentul tricotilomaniei pot include: auto-monitorizare, terapie cognitiv-comportamentală, cursuri de relaxare, psihoterapie, hipnoză. Prognosticul poate varia în funcție de patologia psihică asociată, astfel că unele persoane pot prezenta simptomatologie continua timp de zeci de ani, alteori cursul bolii fiind marcat de remisiuni şi recurente.

În cazul nostru diagnosticul a fost confirmat prin endoscopie digestivă superioară. Extracția tri- cobezoarului a fost realizată prin gastrotomie, printr-o laparotomie minimă subcostală stângă. Deoarece stresul emoțional este de cele mai multe ori factorul declanşator pentru tricofagie sau tricotilomanie evaluarea psihiatrică sau psihologică este esenţială, inclusiv din punct de vedere prognostic. Pacienta noastră a fost direcționată către un serviciu de psihiatrie pentru evaluare şi tratament de specialitate.

\section{CONCLUZII}

Tricobezoarul trebuiat luat în considerare ca posibilitate de diagnostic la pacienții pediatrici cu istoric sugestiv de tricofagie si masă epigastrică palpabila. Diagnosticul se realizeaza prin endoscopie digestivă superioară, care permite uneori şi sancțiune terapeutică. Managementul acestei patologii impune frecvent gestul chirurgical. Abordarea multidisciplinară este esențială întrucât majoritatea acestor pacienți prezintă o tulburare psihiatrică subiacentă. 